\title{
Role for Corticoids in Mediating the Response of Rana pipiens Tadpoles to Intraspecific Competition
}

\author{
KAREN ANN GLENNEMEIER AND ROBERT JOHN DENVER* \\ Department of Biology, University of Michigan, Ann Arbor, Michigan \\ 48109-1048
}

\begin{abstract}
Competition is known to decrease growth and development rate in tadpoles, but the physiological basis for this phenomenon is poorly understood. We hypothesized that competition results in increased production of stress hormones and that these hormones are responsible for the suppression of growth and development. To test this hypothesis, we measured whole-body corticosterone content in premetamorphic Leopard frog (Rana pipiens) tadpoles raised at two different population densities and three different food levels. Whole body corticosterone content was elevated in tadpoles subjected to either limited food (at low density) or high density. Within the low and intermediate food treatments, high density reduced tadpole growth and slowed development. Limited food slowed growth and development at all densities. Blocking corticoid synthesis by treating tadpoles with metyrapone (MTP) reversed the growth suppression caused by high density (tested in the intermediate food level treatment) but did not alter the effect of density on development rate. MTP treatment did not alter the depressive effect of limited resources on growth or development. Our results suggest that elevated corticoid biosynthesis mediates the negative effect of increased population density (i.e., increased intraspecific competition) on tadpole growth. J. Exp. Zool. 292:32-40, 2002. ㅇ 2002 Wiley-Liss, Inc.
\end{abstract}

Competition is well known to affect components of individual fitness in amphibian larvae. Increased competition intensity has been shown to decrease larval growth rate, development rate, survivorship, and size at metamorphosis (Brockelman, '69; Wilbur and Collins, '73; Wilbur, '77; Smith, '87; Berven and Chadra, '88; Scott, '90). Both a longer larval period and a smaller size at metamorphosis can delay adult reproductive maturity, decrease size at first reproduction, and in some cases decrease adult survival to first reproduction (Berven and Gill, '83; Smith, '87; Semlitsch et al., '88). Longer time to metamorphosis also may increase larval exposure time to aquatic predators (Wilbur, '80; Werner, '86) or decrease the chance of metamorphosing before a quicklydrying pond disappears (Newman, '92).

Despite abundant evidence of competition's influence on individual fitness, the physiological mechanisms that translate environmental density or resource cues into growth and developmental responses have not been identified. Much is known about the physiological regulation of amphibian development, but the link has not yet been made between this knowledge and that of the phenomenological effects of competition. Such a link would enhance our understanding of amphibian physiological ecology and our abil- ity to predict competitive outcomes in complex systems.

Amphibian metamorphosis is controlled by thyroid hormone, which induces tissue-specific metamorphic changes (Kikuyama et al., '93). Steroid hormones produced by the amphibian interrenal glands (homologous to avian and mammalian adrenal cortex) also may play a central role in controlling metamorphosis. The production of corticoids by the interrenal glands increases during metamorphosis, more or less in parallel with thyroid hormone, and corticoids are known to synergize with thyroid hormone during pro-metamorphosis to accelerate metamorphic changes (Frieden and Naile, '55; Gray and Janssens, '90; Kikuyama et al., '93; Hayes and $\mathrm{Wu}$, '95). However, corticoids may inhibit or not affect hind limb development of early stage (pre-metamorphic) tadpoles (Kobayashi, '58; Hayes et al., '93), and treatment with ex-

Grant sponsor: Office of the Great Lakes, Michigan Great Lakes Protection Fund. Grant sponsor: University of Michigan Department of Biology and Rackham School of Graduate Studies. Grant sponsor: National Science Foundation; Grant number: IBN9974672.

*Correspondence to: Robert J. Denver, Department of Biology, 3065C Natural Science Building, The University of Michigan, Ann Arbor, MI 48109-1048. E-mail: rdenver@umich.edu

Received 10 October 2000; Accepted 9 July 2001 
ogenous corticosterone slows tadpole growth throughout development (Wright et al., '94; Hayes et al., '93). This growth inhibitory effect of corticoids is common throughout vertebrate taxa, as these hormones serve to mobilize stored fuels and increase metabolism under emergency situations; thus the designation 'stress hormones' (ChesterJones et al., '72; Selye, '73; Munck et al., '84; Schreck, '93; Wingfield, '94).

Circulating corticoid concentrations are elevated in many taxa in response to environmental factors including food deprivation (birds: Cherel et al., '88; Kitaysky et al., '99), extreme weather (birds: Wingfield et al., '97), exercise (mammals and birds: Schreck, '93), crowding (fish: Schreck, '81), social dominance by a conspecific (fish and mammals: Louch and Higgenbotham, '67; Sapolsky, '87; Overli et al., '99), and hibernation (reptiles: Dauphinvillemant et al., '90). However, relatively little is known about environmental influences on corticoid production in amphibians. As in other taxa, corticoids regulate metabolic processes in amphibia and are elevated in response to acute stressors such as handling or confinement (Licht et al., '83; Zerani et al., '91; Moore et al., '94). Both circannual and circadian rhythms in circulating concentrations of corticoids have been measured in amphibians (Licht et al., '83; Jolivet-Jaudet et al., '84; Thurmond et al., '86; Hopkins et al., '97), suggesting some influence of the environment on hormone production. Hayes ('97) measured elevated corticoid content in toad tadpoles held at high densities, and previous work of ours demonstrated a functional role for the neuroendocrine stress axis in mediating the developmental response of Western spadefoot toad tadpoles to pond drying (see Denver, '97, '98). To our knowledge, no other studies have examined directly the influence of environmental factors on corticoid production in amphibians.

We tested the hypothesis that the growth- and developmental responses of Rana pipiens (northern leopard frog) tadpoles to intraspecific competition are mediated through the production of corticoids. We raised tadpoles at different population densities and food levels, measured wholebody corticosterone content, and observed the effect of blocking corticoid synthesis on the tadpoles' growth and developmental responses to competition.

\section{MATERIALS AND METHODS}

$R$. pipiens eggs were purchased from Carolina Biological Supply Co. (Burlington, NC). All experi- ments were done in environmental chambers, maintained at $22^{\circ} \mathrm{C}$ and at $12 \mathrm{~L}: 12 \mathrm{D}$.

\section{Experiment 1: Effects of conspecific density and food level on whole-body corticosterone content}

Premetamorphic tadpoles (Gosner stage 25; Gosner, '60) were placed into plastic tanks containing $4 \mathrm{~L}$ water, at a density of eight or 40 tadpoles per tank, and were fed a ground food mixture of 3:1 Purina Rabbit Chow:Tetramin Fish Flakes, at 18,6 , or $2 \%$ body mass per day (based on the mean mass of animals per tank, weighed weekly). Food levels of 10-15\% body mass per day allow tadpoles to grow at rates similar to those observed in nature, and levels of $7.5 \%$ have been shown to induce resource competition among ranids (Werner, '92). Density and food treatments were fully crossed to give six treatments, with two replicate tanks per treatment. Treatment identifications are $8 \mathrm{H}, 8 \mathrm{M}, 8 \mathrm{~L}, 40 \mathrm{H}, 40 \mathrm{M}$, and $40 \mathrm{~L}$, corresponding to low (8) versus high (40) density and high $(\mathrm{H})$, intermediate $(\mathrm{M})$, or low (L) food levels, respectively. Tadpoles were fed on days one and three. On day four, ten tadpoles from each treatment (five from each replicate tank) were randomly selected and immediately anesthetized by submersion in $0.01 \%$ benzocaine. Tadpoles were weighed and frozen at $-20^{\circ} \mathrm{C}$ for later extraction and analysis of whole-body corticosterone content by radioimmunoassay (RIA; see below).

\section{Experiment 2: Effects of conspecific density, food level, and metyrapone on growth and development}

Premetamorphic tadpoles (Gosner stage 25) were weighed and placed into $4 \mathrm{~L}$ plastic tanks at the densities and food levels described for Experiment 1. Additional treatments added metyrapone (MTP; Sigma-Aldrich, St. Louis, MO), a corticoid synthesis inhibitor, to some of these density/food combinations. Not all density/food combinations could be treated with MTP, due to limited availability of the compound, so we chose to add MTP to four of the six density/food combinations: $8 \mathrm{H}$, $8 \mathrm{M}, 8 \mathrm{~L}$, and $40 \mathrm{M}$. Comparison among the $8 \mathrm{H}, 8 \mathrm{M}$, and $8 \mathrm{~L}$ groups allowed us to observe the effect of decreased corticoid biosynthesis on growth or developmental responses to limited food levels. Comparison between the $8 \mathrm{M}$ and $40 \mathrm{M}$ groups allowed us to observe the effect of decreased corticoid biosynthesis on any responses to high density. Three replicate tanks were included for all ten treatments. Water in all tanks was changed twice 
weekly, and tadpoles were fed every 1-3 days. MTP was dissolved in ethanol and added to the tanks following water change, to give a final concentration of $110 \mu \mathrm{M}$ MTP in the water. Non-MTP tanks received ethanol only. Ethanol concentration in the water was $0.0043 \%$ of total water volume. MTP concentration was determined based on Hayes and $\mathrm{Wu}$ ('95), who found that $22 \mu \mathrm{M}$ MTP reduced whole-body corticosterone content of toad tadpoles by $33 \%$. Our goal was $100 \%$ reduction of $R$. pipiens whole-body corticosterone content.

After 17 days at the different densities, food levels, and MTP treatments, all tadpoles were weighed, staged, and then returned to their respective tanks. At 52 days, as the first individuals began to reach metamorphic climax, all tadpoles were anesthetized by submersion in $0.01 \%$ benzocaine. Seven tadpoles from each treatment were randomly selected from the three replicate tanks, weighed, staged, euthanized, and frozen at $-20^{\circ} \mathrm{C}$ for later extraction and analysis of corticosterone by RIA. All other tadpoles were weighed and staged only.

\section{Tissue extraction and corticosterone RIA}

The extraction procedure is described by Hayes and Wu ('95) and Denver ('98). Briefly, tissues were homogenized in ethyl acetate and the extracts fractionated by thin layer chromatography (TLC) to separate corticosterone from other lipids. The region of the TLC lane containing the corticosterone (as determined by calibration with both radiolabeled and radioinert corticosterone; see Denver, '98) was scraped and the silica collected into a borosilicate glass tube. The silica was extracted with ethyl ether, and the extract was dried under nitrogen and then resuspended in PBS-gelatin (PBS-G; $0.02 \mathrm{M}, \mathrm{pH}$ 7.3) for corticosterone RIA. The RIA was conducted as described by Licht et al. ('83). Anti-corticosterone serum was purchased from Endocrine Sciences (Calabasas, CA) and $\left[{ }^{3} \mathrm{H}\right]$-corticosterone from NEN Life Science Products, Inc. (Boston, MA). Samples from a single experiment were analyzed in a single RIA or in multiple RIAs on a single day. Inter- and intra-assay coefficients of variation were $12 \%$ and $10 \%$, respectively, and were monitored by including a quality control standard (pooled rat plasma) in each RIA. Tadpole extracts exhibited parallelism in the RIA.

\section{Data analysis and statistics}

Data for corticosterone content in experiment 1 were analyzed by two-way ANOVA, with whole- body corticosterone content as the response variable and food level and population density as treatments. For experiment 2, the effect of treatment on growth within non-MTP treatments was analyzed using two-way ANOVA, with relative growth as the response variable and food level and density as treatments. Multiple comparisons were not conducted on the main effects since the interaction terms were significant in all cases (see Results).

\section{Calculation of relative growth}

Relative growth was calculated by subtracting the mean initial mass of tadpoles within a tank from the mean final mass of tadpoles within that tank and dividing this difference by the mean initial mass. Measures of relative growth for animals in replicate tanks were averaged to provide an overall mean relative growth for the treatment ( $\mathrm{n}$ $=3$; sample unit was the tank mean). For effects of MTP on the growth response to competition, two one-way ANOVAs were conducted. The first compared relative growth among the six treatments: $8 \mathrm{H}$ no MTP, $8 \mathrm{H}$ with MTP, $8 \mathrm{M}$ no MTP, $8 \mathrm{M}$ with MTP, $8 \mathrm{~L}$ no MTP, and 8L with MTP, to evaluate the degree to which MTP altered the growth response to limited resources. The second compared relative growth among the four treatments: $8 \mathrm{M}$ no MTP, 8M with MTP, 40M no MTP, and $40 \mathrm{M}$ with MTP, to evaluate the degree to which MTP altered the growth response to density. Pairwise comparisons following these one-way ANOVAs utilized a Bonferroni correction to account for multiple comparisons. For one-way ANOVAs and pairwise comparisons, we set $\alpha=$ 0.025 , to account for the fact that the two ANOVAs analyzed some common data.

Effect of treatment on development rate within non-MTP treatments was analyzed using two-way ANOVA, with Gosner stage as the response variable and food level and density as treatments. For effects of MTP on the developmental response to competition, two one-way ANOVAs were conducted as described for growth data, with developmental stage as the response variable.

To evaluate the degree to which MTP treatment reduced whole-body corticosterone content in chronically treated tadpoles, Student's $t$-test was used to compare corticosterone content of tadpoles from tanks with and without MTP treatment within each density/food level treatment.

Day 52 percent survivorship among treatments was analyzed with two-way ANOVA, with fraction survivorship (arcsine square root transformed) 
as the response variable and density and food level as treatments. High mortality within the high density treatments precluded any quantitative analysis of day 52 growth and development data.

\section{RESULTS \\ Experiment 1: Whole-body corticosterone content}

Whole-body corticosterone content of $R$. pipiens tadpoles was elevated following short term exposure to both limited resources and increased density (Fig. 1). Two-way ANOVA showed significant main effects of food level $\left(\mathrm{F}_{2,45}=7.6 ; P=0.001\right)$ and density $\left(\mathrm{F}_{1,45}=9.6 ; P=0.003\right)$ and a significant interaction between the two $\left(\mathrm{F}_{2,45}=7.0 ; P=0.002\right)$.

\section{Experiment 2: Growth}

Lower food levels caused lower growth rates within both densities (Fig. 2, top panel). Within the intermediate and low food treatments, high conspecific density decreased tadpole growth after 17 days, while within the high food group, higher density was associated with greater growth (Fig. 2, top panel). Two-way ANOVA showed a significant main effect of food level $\left(\mathrm{F}_{2,12}=153 ; P<\right.$ $0.00005)$ but no main effect of density $\left(\mathrm{F}_{1,12}=2.1\right.$; $P=0.17$ ), with a significant interaction between food level and density $\left(\mathrm{F}_{2,12}=35.3 ; P<0.00005\right)$.

Inhibition of corticoid biosynthesis by MTP did not affect growth within the low density treatment at the three food levels (Fig. 2, middle). However, while MTP did not ameliorate the depressive effect of limited resources on growth, it did ameliorate that of density. In the absence of MTP, high conspecific density depressed growth compared to

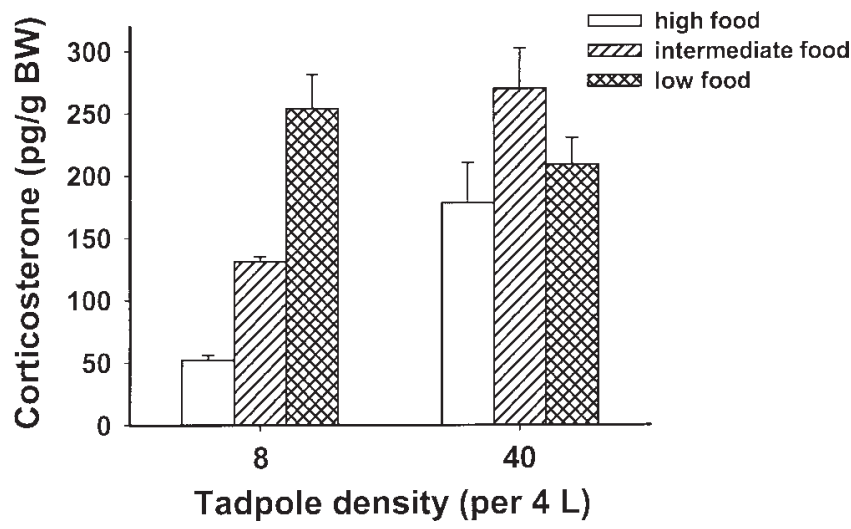

Fig. 1. Whole-body corticosterone content of $R$.. pipiens tadpoles after four days at varying densities and food levels. Error bars represent standard errors of the mean of individual tadpoles ( $\mathrm{n}=8-10 ; 8 \mathrm{M}$ group, $\mathrm{n}=4$, due to radioimmunoassay values outside of optimal binding range).
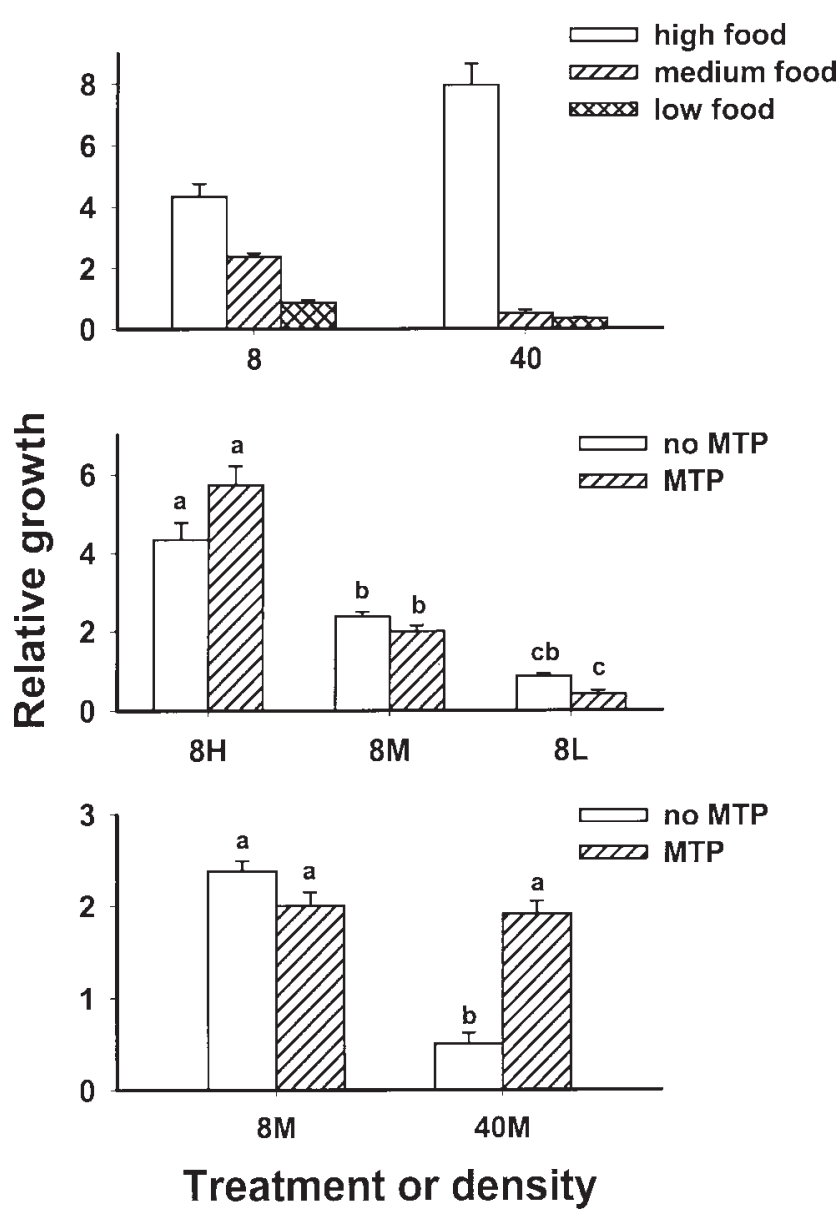

Fig. 2. Relative growth of $R$.. pipiens tadpoles after 17 days at varying densities and food levels. Top panel: treatments without metyrapone (MTP). Middle panel: effect of MTP on growth among varying food levels, at the same density ('no MTP' bars are identical to those in top panel). Bottom panel: effect of MTP on growth between different densities, at the same food level ('no MTP' bars are identical to those in top panel, and 8M MTP group is identical to that shown in middle panel). See Materials and Methods for treatment abbreviations and for the calculation of relative growth. Different letters above the bars represent means that are significantly different from one another $(P<0.025)$. Means of bars with the same letter do not differ. Error bars represent standard errors of the mean of three replicate tanks.

the low density group, but in the presence of MTP, growth in the high density and low density groups did not differ (one-way ANOVA $\mathrm{F}_{3,8}=40 ; P<$ 0.00005 ; Fig. 2, lower panel).

\section{Experiment 2: Development}

High density slowed tadpole development within the intermediate food treatment but was associated with accelerated development within the high food group (Fig. 3, top panel). Lower food levels slowed development within both densities (Fig. 3, 

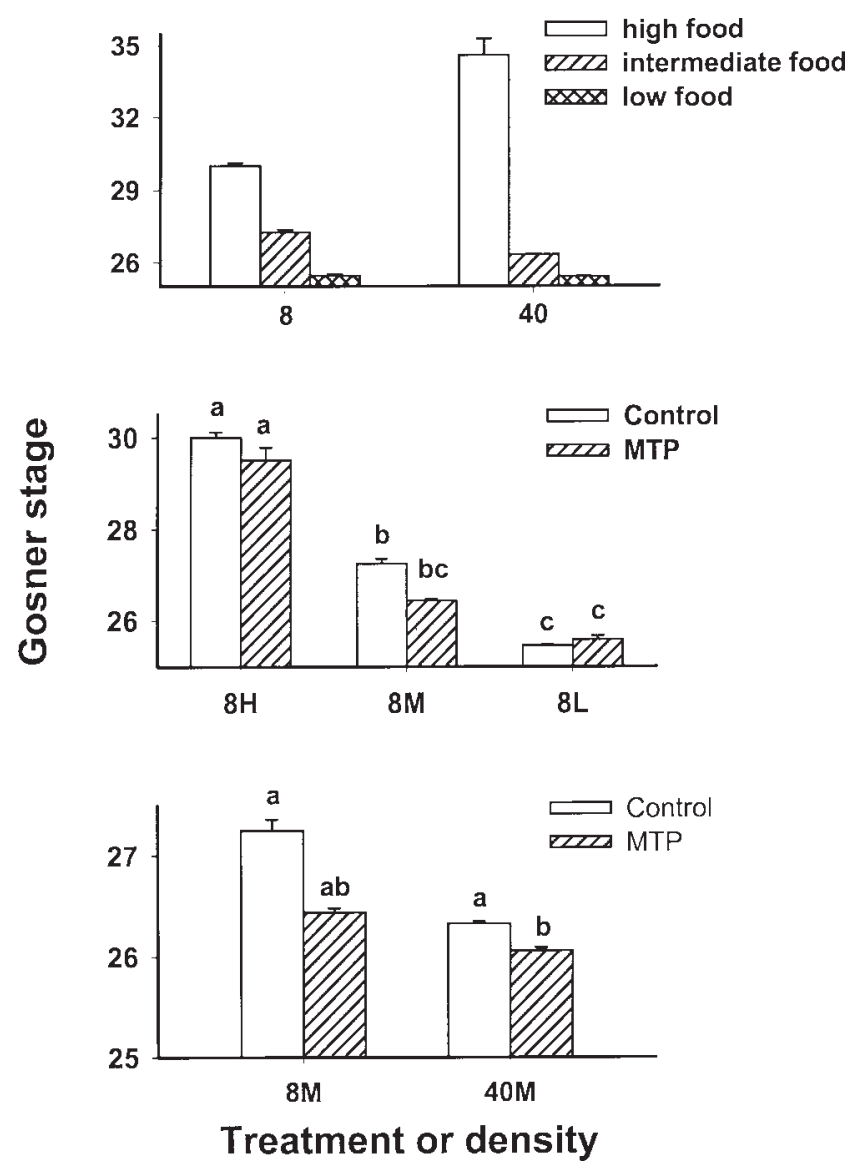

Fig. 3. Developmental stage (Gosner, '60) of R.. pipiens tadpoles after 17 days at varying densities and food levels. Top panel: treatments without metyrapone (MTP). Middle panel: effect of MTP on development among varying food levels, at the same density ('no MTP' bars are identical to those in top panel). Bottom panel: effect of MTP on density between different densities, at the same food level ('no MTP' bars are identical to those in top panel, and 8/M MTP group is identical to that shown in middle panel). See Materials and Methods for treatment abbreviations. Different letters above the bars represent means that are significantly different from one another $(P<0.025)$. Means of bars with the same letter do not differ. Error bars represent standard errors of the mean of individual tadpoles ( $\mathrm{n}=22-116$; sample sizes vary due to differences in treatment density and mortality).

top panel). Two-way ANOVA showed a significant main effect of food level $\left(\mathrm{F}_{2,330}=348 ; P<0.00005\right)$ but no main effect of density $\left(\mathrm{F}_{1,330}=0.55 ; P=\right.$ 0.46 ), with a significant interaction between food level and density $\left(\mathrm{F}_{2,330}=7.8 ; P=0.0005\right)$. Blocking corticoid synthesis with MTP did not alter the negative effect of limited resources on development (Fig. 3, middle panel). MTP treatment did not reverse the negative (though nonsignificant) effect of density on development but instead appeared to slow development compared to the non-
MTP groups (one-way ANOVA $\mathrm{F}_{3,217}=12 ; P<$ 0.00005; Fig. 3, lower panel).

\section{Experiment 2: Corticosterone content with MTP treatment; day 52 survivorship}

Corticosterone content of MTP-treated tadpoles was lower than that of untreated tadpoles after 52 days of treatment but was still measurable (Fig. 4). Survivorship at day 52 was significantly lower in high density groups compared to low density (Fig. 5, two-way ANOVA: density $\mathrm{F}_{1,12}=26, P$ $<0.0005$; food $\mathrm{F}_{2,12}=0.39, P=0.69$; interaction $\left.\mathrm{F}_{2,12}=1.6, P=0.24\right)$. While high mortality precluded a quantitative analysis of growth and developmental responses, the patterns we observed at day 52 within low density groups were qualitatively similar to those presented for day 17.

\section{DISCUSSION}

We have shown that short term exposure (four days) to either increased conspecific density or limited resource levels elevated whole-body corticosterone content in $R$. pipiens tadpoles. This corticosterone elevation appears to be responsible for the depressive effect of density on growth but not on development, and does not mediate the effect of food limitation on growth or development. This study is the first to identify a physiological factor that varies with increased intensity of com-

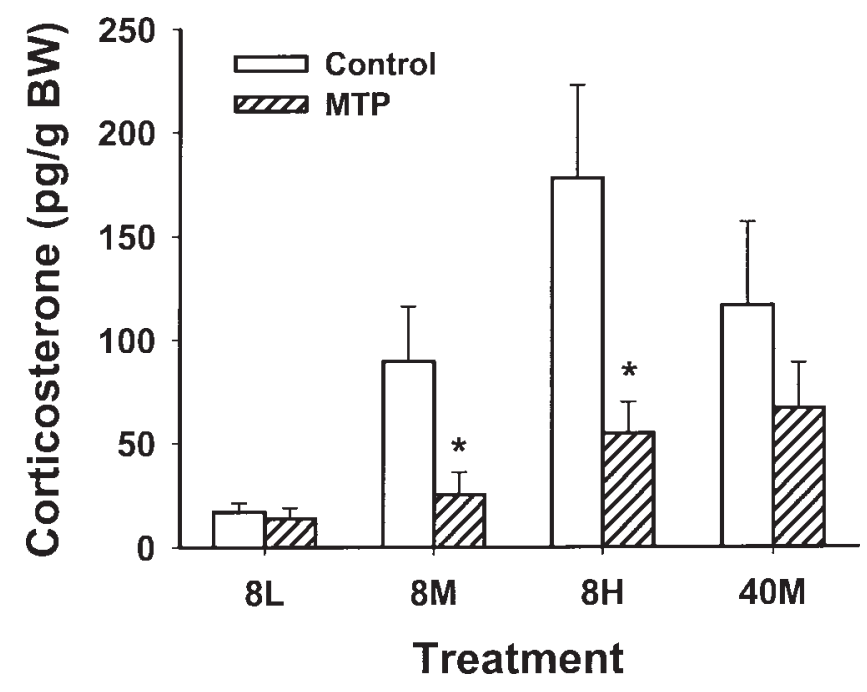

Fig. 4. Whole-body corticosterone content of $R$.. pipiens tadpoles after 52 days at varying densities and food levels, with or without metyrapone (MTP). Asterisks (*) indicate significant difference of MTP-treated group from non-MTP group within each density/food level treatment $(P<0.05)$. Error bars represent standard errors of the mean of individual tadpoles ( $\mathrm{n}=6-7 ; 8 \mathrm{~L} / \mathrm{MTP}$ group, $\mathrm{n}=4$, due to radioimmunoassay values outside of optimal binding range). 


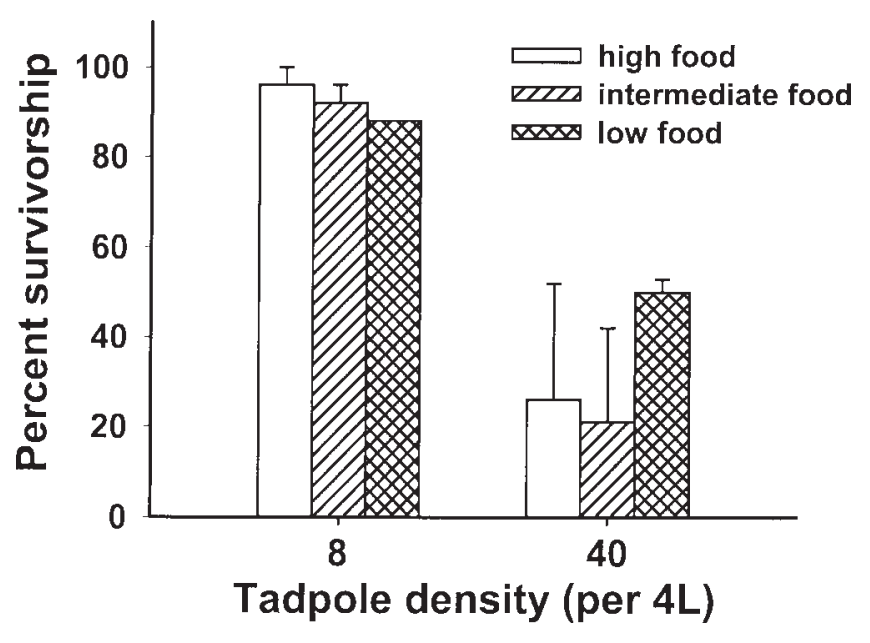

Fig. 5. Percent survivorship of $R$. pipiens tadpoles after 52 days at varying densities and food levels. Error bars represent standard errors of the mean of three replicate tanks.

petition in larval amphibians. Hayes ('97) reported an elevation in whole-body corticosterone content of Bufo boreas tadpoles held at five-fold higher densities than controls, with ad libitum food levels. In the current study, we separated competition into the two components of increased density and resource limitation, and found that each was associated with elevated corticosterone content.

Competition is well known to inhibit growth and reproduction, and our results are consistent with these findings. That tadpoles in the $40 \mathrm{H}$ treatment exhibited higher growth rates than those in the $8 \mathrm{H}$ treatment could represent an Allee effect (Allee, '31), whereby increased density facilitates growth up to some threshold density and inhibits growth thereafter. Other studies have also found positive effects of density over some density ranges in tadpoles (Brockelman, '69; Travis and Trexler, '86). Wilbur ('77) observed such an effect in toad tadpoles, with a negative correlation between growth and density becoming apparent only at densities above 40 tadpoles per 2 L. Beiswenger ('75) concluded that facilitation among toad tadpoles occurred through physical interactions that stirred and suspended the food, making it more available for consumption. While this stirring mechanism has not been studied in $R$. pipiens tadpoles, several studies suggest that physical interactions are important mediators of competitive growth effects in this species (Rugh, '34; Gromko et al., '73). If the stirring mechanism were acting in the current experiment, food levels in the $40 \mathrm{M}$ and $40 \mathrm{~L}$ treatments might not have been sufficient for tadpoles to benefit from such physical interactions, while food levels in the $40 \mathrm{H}$ treatments may have been sufficient for this mechanism to act. Travis and Trexler ('86) found negative density effects in toad tadpoles within environments of poor physical quality but positive density effects in high-quality environments, and others have shown negative density effects to be more pronounced in physically stressful environments (Watkinson, '82). In our experiment, density negatively affected growth at intermediate and low food levels, and our results with MTP at the intermediate food level suggest that the mechanism may involve the endocrine stress axis.

For tadpoles fed at the intermediate food level, the negative effect of density on growth was reversed by MTP treatment (Fig. 2, bottom panel), suggesting that the elevated corticosterone content associated with increased density (see Fig. 1) produced the observed growth depression. However, the deceleration of development observed in the $40 \mathrm{M}$ compared to the $8 \mathrm{M}$ group was not reversed by MTP (Fig. 3, bottom panel), suggesting that the developmental response was not mediated by corticoids. Instead, MTP slowed development at both densities. Treatment of pre-metamorphic tadpoles with corticoids inhibited growth but not development (Gray and Janssens, '90; Hayes et al., '93; Wright et al., '94; Hayes, '95), and our findings support a physiological role for corticoids in growth suppression caused by crowding when resources are limited. The inhibition of development by MTP in our study suggests that some amounts of endogenous corticoids are necessary for development. These results support the findings of Kikuyama et al. ('82), who concluded that endogenous corticoids are necessary to sustain tadpole development. They showed that treatment with amphenone B (a corticoid synthesis inhibitor) retarded T4-induced tail regression in toad tadpoles (under thiourea treatment to avoid possible effects of amphenone B on endogenous thyroid hormone concentrations), and that this effect was reversed by treatment with corticoids.

While the growth response to high density was reversed by MTP treatment, neither the growth nor the developmental response to limited resources was affected by MTP treatment, suggesting that corticoids do not mediate these responses to limited resources. If corticoids were mediating these responses, the values in the 8M-MTP and 8L-MTP treated groups should have approached those of the high food group at the same density (8H; see Figs. 2-3, middle panels). The response to limited resources is likely due to metabolic con- 
straints involving insufficient nutrients for structural growth or development. Resource limitation is known to elevate plasma corticoid concentrations in other taxa, which serves to mobilize spare fuel in fasting animals (Selye, '73; Munck et al., '84; Wingfield, '94; Kuhn et al., '98). While MTP treatment should reduce such catabolic activity, overall growth and development could still be limited by insufficient resources.

While corticosterone did not mediate the developmental response to competition or the growth response to limited resources, the significant increase in corticosterone content with both limited resources and high density raise the possibility that other physiological or behavioral responses besides growth and development could be influenced by this corticosterone increase. For example, corticosterone is known to affect behavior in other taxa (Moore and Zoeller, '85; Silverin, '86; DeNardo and Sinervo, '94; Wingfield et al., '97), and the presence of competitors has been shown to influence tadpole behavior (Skelly, '92; Anholt and Werner, '95). Direct studies of corticosterone's effect on tadpole behavior, and the interaction of any effects with competitor presence, would clarify the degree to which elevated corticosterone mediates tadpole behavioral responses to competitors.

In addition to the information the current results provide about the mechanisms of competitive response, they may also yield insight concerning the factors that ultimately determine the timing of metamorphosis. Wilbur and Collins ('73) proposed that development rate, and thus the length of the larval period, responded to growth rate throughout the larval period, and that any effect of environmental factors (such as competition, predation, pond drying, etc.) on development rate would be mediated through effects on individual growth rate. Smith-Gill and Berven ('79) and Travis ('84) noted that rates of growth and development are imperfectly correlated and suggested that each rate varies independently in response to the environment. Our results are consistent with the latter hypothesis, as we were able to dissociate the developmental response to density from the growth response. While growth was accelerated by MTP treatment in the $40 \mathrm{M}$ group, development was unchanged compared with the non-MTP group. This pattern suggests that growth rate per se does not dictate development rate, but that perhaps some physiological factor (other than corticosterone; e.g., thyroid activity) alters development in response to environmental conditions. Further insight into theoretical questions about control of metamorphic timing is likely to be gained through additional studies of endocrine responses to environmental conditions. Hormones interact in complex ways to orchestrate tadpole growth and development (Kikuyama et al., '93), with specific actions changing over development and in the presence of other hormones. Given the responsiveness of the hypothalamo-pituitary-interrenal (HPI) axis to competitive intensity and to pond drying (Denver, '97; '98), this axis may prove to be a common mediator of tadpoles' developmental responses to their environment.

Figure 4 demonstrates that MTP lowered wholebody corticosterone content after 52 days but did not produce $100 \%$ reduction. While higher MTP doses might further reduce corticosterone content, feedback mechanisms may prevent complete reduction of whole-body corticoids by treatment with a static dose of MTP. A reduction in corticoid production would reduce negative feedback on the hypothalamus/pituitary and thus increase stimulation of the interrenal glands (Axelrod and Reisine, '84; Keller-Wood and Dallman, '84; Munck et al., '84). Consequently, an increasing dose of MTP might be required to fully suppress corticoid production by this strengthening signal. The non-MTP-treated groups in Fig. 4 show a corticosterone pattern reversed from that shown in Fig. 1 , due to the fact that, after 52 days, tadpoles at lower densities and higher food levels had reached later developmental stages than those at high density or low food levels. Whole-body corticosterone content increases as development progresses in $R$. pipiens and other ranid tadpoles (Krug et al., '83; Glennemeier and Denver, unpublished data). The short-term corticosterone response to competition shown in Fig. 1 was not confounded by developmental stage, as all tadpoles were at Gosner stage 25. Mortality at day 52 was higher in high density groups compared to low density groups, consistent with other studies of density-dependent larval survivorship (Wilbur, '80; Smith, '87).

\section{CONCLUSIONS}

We have identified a proximate mediator of the growth response to competition in $R$. pipiens tadpoles. Other mediators may include hormones associated with the endocrine stress axis (e.g., hypothalamic and pituitary hormones), as this axis has been shown to mediate responses to environmental change in tadpoles and other taxa (Wingfield et al., '97; Denver, '98; Overli et al., '99). Further knowledge of tadpole physiological ecology promises to provide a valuable tool for pre- 
dicting the outcomes of species interactions. Processes such as predation and competition are known to interact in complex ways to influence fitness in larval amphibians (Werner, '91; Anholt and Werner, '95; Werner and Anholt, '96). The identification of one or more common physiological mediators through which tadpoles respond to predators, competitors, or other environmental factors may help to simplify hypotheses about how these processes interact and may improve predictions of community-level outcomes.

\section{ACKNOWLEDGMENTS}

We wish to thank Robert Bartel, Graham Boorse, and Amanda Long for help with animal care and data collection. The University of Michigan Biology department provided physical support and animal care facilities.

\section{LITERATURE CITED}

Allee WC. 1931. Animal aggregations. A study in general sociology. Chicago: University of Chicago Press.

Anholt BR, Werner EE. 1995. Interaction between food availability and predation mortality mediated by adaptive behavior. Ecology 76:2230-2234.

Axelrod J, Reisine TD. 1984. Stress hormones: their interaction and regulation. Science 224:452-459.

Beiswenger RE. 1975. Structure and function in aggregation of tadpoles of the American toad, Bufo americanus. Herpetologica 31:222-233.

Berven KA, Chadra BG. 1988. The relationship among egg size, density, and food level on larval development in the wood frog (Rana sylvatica). Oecologia 75:67-72.

Berven KA, Gill DE. 1983. Interpreting geographic variation in life-history traits. Am Zool 23:85-97.

Brockelman WY. 1969. An analysis of density effects and predation in Bufo americanus tadpoles. Ecology 50:632-644.

Cherel Y, Robin J, LeMaho Y. 1988. Physiology and biochemistry of long-term fasting in birds. Can J Zool 66:159-166.

Chester-Jones I, Bellamy D, Chan DKO, Follett BK, Henderson IW, Phillips JG, Snart RS. 1972. Biological actions of steroid hormones in nonmammalian vertebrates. In: Idler DR, editor. Steroids in non-mammalian vertebrates. New York: Academic Press. p 414-480.

Dauphinvillemant C, Leboulenger F, Vaudry H. 1990. Adrenal activity in the female lizard Lacerta vivipara jacquin during artificial hibernation. Gen Comp Endocrinol 79:201-214.

DeNardo DF, Sinervo B. 1994. Effects of steroid hormone interaction on activity and home range size of male lizards. Horm Behav 28:273-287.

Denver RJ. 1997. Environmental stress as a developmental cue: corticotropin-releasing hormone is a proximate mediator of adaptive phenotypic plasticity in amphibian metamorphosis. Horm Behav 31:169-179.

Denver RJ. 1998. Hormonal correlates of environmentally induced metamorphosis in the western spadefoot toad, Scaphiopus hammondii. Gen Comp Endocrinol 110:326-336.

Frieden E, Naile B. 1955. Biochemistry of amphibian metamorphosis: I. Enhancement of induced metamorphosis by gluco-corticoids. Science 121:37-39.
Gosner KL. 1960. A simplified table for staging anuran embryos and larvae with notes on identification. Herpetologica 16:183-190.

Gray KM, Janssens PA. 1990. Gonadal hormones inhibit the induction of metamorphosis by thyroid hormones in Xenopus laevis tadpoles in vivo, but not in vitro. Gen Comp Endocrinol 77:202-211.

Gromko MH, Mason FS, Smith-Gill SJ. 1973. Analysis of the crowding effect in Rana pipiens tadpoles. J Exp Zool 186:63-72.

Hayes TB. 1995. Interdependence of corticosterone and thyroid hormones in larval toads (Bufo boreas). I. Thyroid hormone-dependent and independent effects of corticosterone on growth and development. J Exp Zool 271:95-102.

Hayes TB. 1997. Steroids as potential modulators of thyroid hormone activity in anuran metamorphosis. Am Zool 37: 185-194.

Hayes TB, Wu TH. 1995. Interdependence of corticosterone and thyroid hormones in toad larvae (Bufo boreas). II. Regulation of corticosterone and thyroid hormones. J Exp Zool 271:103-111.

Hayes TB, Chan R, Licht P. 1993. Interactions of temperature and steroids on larval growth, development, and metamorphosis in a toad (Bufo boreas). J Exp Zool 266:206-215.

Hopkins WA, Mendonca MT, Congdon JD. 1997. Increased circulating levels of testosterone and corticosterone in southern toads, Bufo terrestris, exposed to coal combustion waste. Gen Comp Endocrinol 108:237-246.

Jolivet-Jaudet G, Inoue M, Takada K, Ishii S. 1984. Circannual changes in corticosterone plasma levels and binding of corticosterone to plasma in Bufo japonicus formosus. Zoological Science 1:317-326.

Keller-Wood ME, Dallman MF. 1984. Corticosteroid inhibition of ACTH secretion. Endocr Rev 5:1-24.

Kikuyama S, Niki K, Mayumi M, Kawamura K. 1982. Retardation of thyroxine-induced metamorphosis by amphenone B in toad tadpoles. Endocrinol Japonica 29:659-662.

Kikuyama S, Kawamura K, Tanaka S, Yamamoto K. 1993. Aspects of amphibian metamorphosis: hormonal control. Int Rev Cytol 145:105-148.

Kitaysky AS, Piatt JF, Wingfield JC, Romano M. 1999. The adrenocortical stress-response of Black-legged Kittiwake chicks in relation to dietary restrictions. J Comp Physiol [B] 8:303-310.

Kobayashi H. 1958. Effect of deoxycorticosterone acetate on metamorphosis induced by thyroxine in anuran tadpoles. Endocrinology 62:371-377.

Krug EC, Honn KV, Battista J, Nicoll CS. 1983. Corticosteroids in serum of Rana catesbeiana during development and metamorphosis. Gen Comp Endocrinol 52:232-241.

Kuhn ER, Geris KL, van der Geyten S, Mol KA, Darras VM. 1998. Inhibition and activation of the thyroidal axis by the adrenal axis in vertebrates. Comp Biochem Physiol A Physiol 20:169-174.

Licht P, McCreery BR, Barnes R, Pang R. 1983. Seasonal and stress related changes in plasma gonadotropins, sex steroids, and corticosterone in the bullfrog, Rana catesbeiana. Gen Comp Endocrinol 50:124-145.

Louch CD, Higgenbotham M. 1967. The relation between social rank and plasma corticosterone levels in mice. Gen Comp Endocrinol 8:441-444.

Moore FL, Zoeller RT. 1985. Stress-induced inhibition of reproduction: evidence of suppressed secretion of LH-RH in an amphibian. Gen Comp Endocrinol 60:252-258.

Moore FL, Lowry CA, Rose JD. 1994. Steroid-neuropeptide 
interactions that control reproductive behaviors in an amphibian. Psychoneuroendocrinology 19:581-592.

Munck A, Guyre PM, Holbrook NJ. 1984. Physiological functions of glucocorticoids in stress and their relation to pharmacological actions. Endocr Rev 5:25-44.

Newman RA. 1992. Adaptive plasticity in amphibian metamorphosis. Bioscience 42:671-678.

Overli O, Harris CA, Winberg S. 1999. Short-term effects of fights for social dominance and the establishment of dominant-subordinate relationships on brain monoamines and cortisol in rainbow trout. Brain Behav Evol 54:263-275.

Rugh R. 1934. The space factor in the growth rate of tadpoles. Ecology 15:407-411.

Sapolsky RM. 1987. Stress, social status, and reproductive physiology in free-living baboons. In: Crews D, editor. Psychobiology of reproductive behavior: an evolutionary perspective. New Jersey: Prentice Hall, Englewood Cliffs. p 291-322.

Schreck CB. 1981. Stress and compensation in teleostian fishes: response to social and physical factors. In: Pickering $\mathrm{AD}$, editor. Stress and fish. New York: Academic Press, Inc. p 295-322.

Schreck CB. 1993. Glucocorticoids: metabolism, growth, and development. In: Schreibman MP, Scanes CG, Pang PKT, Schreibman MP, editors. The endocrinology of growth, development, and metabolism in vertebrates. San Diego: Academic Press, Inc. p 367-386.

Scott DE. 1990. Effects of larval density in Ambystoma opacum: an experiment in large-scale field enclosures. Ecology 71:296-306.

Selye H. 1973. The evolution of the stress concept. American Scientist 61:692-699.

Semlitsch RD, Scott DE, Pechmann JHK. 1988. Time and size at metamorphosis related to adult fitness in Ambystoma talpoideum. Ecology 69:184-192.

Silverin B. 1986. Corticosterone-binding proteins and behavioral effects of high plasma levels of corticosterone during the breeding period. Gen Comp Endocrinol 64:67-74.

Skelly DK. 1992. Field evidence for a cost of behavioral antipredator response in a larval amphibian. Ecology 73: 704-708.

Smith HM. 1987. Adult recruitment in chorus frogs: effects of size and death at metamorphosis. Ecology 68:344-350.

Smith-Gill SJ, Berven KA. 1979. Predicting amphibian metamorphosis. Am Nat 113:563-585.

Thurmond W, Kloas W, Hanke W. 1986. Circadian rhythm of interrenal activity in Xenopus laevis. Gen Comp Endocrinol 61:260-271.
Travis J. 1984. Anuran size at metamorphosis: experimental test of a model based on intraspecific competition. Ecology 65:1155-1160.

Travis J, Trexler JC. 1986. Interactions among factors affecting growth, development and survival in experimental populations of Bufo terrestris (Anuran: Bufonidae). Oecologia 69:110-116.

Watkinson. 1982. Factors affecting density response of Vulpia fasciculata. J Ecology 70:149-161.

Werner EE. 1986. Amphibian metamorphosis: growth rate, predation risks, optimal size at transformation. Am Nat 128:319-341.

Werner EE. 1991. Nonlethal effects of a predator on competitive interactions between two anuran larvae. Ecology 72:1709-1720.

Werner EE. 1992. Competitive interactions between wood frog and northern leopard frog larvae: the influence of size and activity. Copeia 1992:26-35.

Werner EE, Anholt BR. 1996. Predator-induced behavioral indirect effects: consequences to competitive interactions in anuran larvae. Ecology 77:157-169.

Wilbur HM. 1977. Density-dependent aspects of growth and metamorphosis in Bufo americanus. Ecology 58:196-200.

Wilbur HM. 1980. Complex life cycles. Annu Rev Ecol Syst 11:67-93.

Wilbur HM, Collins JP. 1973. Evolutionary aspects of amphibian metamorphosis. Science 182:1305-1314.

Wingfield JC. 1994. Modulation of the adrenocortical response to stress in birds. In: Davey KG, Peter RE, Tobe SS, editors. Perspectives in comparative endocrinology. Ottawa: National Research Council Canada. p 520-528.

Wingfield JC, Hunt K, Breuner C, Dunlap K, Fowler GS, Freed L, Lepson J. 1997. Environmental stress, field endocrinology, and conservation biology. In: Clemmons JR, Buchholz $\mathrm{R}$, editors. Behavioral approaches to conservation in the wild. Cambridge: Cambridge University Press. p 95-131.

Wright ML, Cykowski LJ, Lundrigan L, Hemond KL, Kochan DM, Faszewski EE, Anuszewski CM. 1994. Anterior pituitary and adrenal cortical hormones accelerate or inhibit tadpole hindlimb growth and development depending on stage of spontaneous development or thyroxine concentration in induced metamorphosis. J Exp Zool 270:175-188.

Zerani M, Amabili F, Mosconi G, Gobbetti A. 1991. Effects of captivity stress on plasma steroid-levels in the green frog, Rana esculenta, during the annual reproductive cycle. Comp Biochem Physiol A Physiol 98:491-496. 